DOI: 10.15593/RZhBiomeh/2016.2.05

УДК 531/534:[57+61]

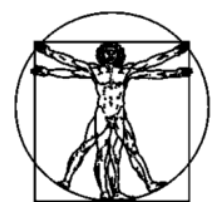

Росеийекий Журнал Биомеханики www.biomech.ru

\title{
БИОМЕХАНИЧЕСКОЕ И НЕЙРОФИЗИОЛОГИЧЕСКОЕ ОБОСНОВАНИЕ ПРИМЕНЕНИЯ ФАЗОВОЙ ЭЛЕКТРИЧЕСКОЙ СТИМУЛЯЦИИ МЫШЦ У ДЕТЕЙ С ГЕМИПАРЕТИЧЕСКОЙ ФОРМОЙ ДЕТСКОГО ЦЕРЕБРАЛЬНОГО ПАРАЛИЧА
}

\author{
А.С. Витензон ${ }^{1}$, К.А. Петрушанская ${ }^{2}$, Г.П. Гриценко ${ }^{1}$, \\ В.С. Шалыгин ${ }^{3}$, И.А. Сутченков ${ }^{3}$
}

\footnotetext{
${ }^{1}$ Федеральное бюро медико-социальной экспертизы, 127486, Россия, Москва, ул. Ивана Сусанина, 3, e-mail: fbmse@fbmse.ru

${ }^{2}$ Российский реабилитационный центр «Детство», 142031, Россия, Московская область, Ленинский район, поселок санатория «Горки Ленинские», e-mail: info@rrcdetstvo.ru

${ }^{3}$ Научно-медицинская фрирма «МБН», 105120, Россия, Москва, 2-й Сыромятнический переулок, 10, e-mail: info@mbn.ru
}

\begin{abstract}
Аннотация. Данная работа посвящена биомеханическому и электромиографическому обоснованию применения фразовой электрической стимуляции мышц у детей с гемипаретической формой ДЦП (форма детского церебрального паралича, при которой двигательные расстройства более выражены в одной стороне тела). Под наблюдением находились две группы детей с данной формой ДЦП различного возраста - 8-10 лет (13 детей) и 13-14 лет (12 детей). Наши исследования показали, что возраст у данного контингента больных имеет принципиальное значение при разработке различных реабилитационных программ, в том числе программы фазовой электрической стимуляции мышц при ходьбе. Ходьба детей обеих групп характеризуется снижением скорости, темпа и длины шага, уменьшением устойчивости, асимметрией временных, кинематических, динамических и электромиографических параметров. Тем не менее у больных первой группы отмечается бо́льшая симметрия биомеханических и особенно электромиографических параметров. В частности, у них наблюдается общее симметричное снижение активности мышц нижних конечностей с акцентом на мышцы дистальных отделов ног. У больных второй группы оказывается сформированным более компенсированный вид гемипаретической походки, при которой дефект имеет отчетливый односторонний дистальный характер и в значительной мере возмещается усилением работы мышц проксимальных отделов нижних конечностей. Полученные результаты указывают на необходимость дифференцированного подхода к реабилитации детей с гемипаретической формой ДЦП в зависимости от возраста. В частности, реабилитация детей младше 10 лет должна осуществляться так же, как у детей с диплегической формой ДЦП (форма детского церебрального паралича, при которой наблюдается двусторонний паралич одноименных частей тела). В аспекте применения фазовой электрической стимуляции это означает, что основным воздействием является коррекция разгибания и отведения в обоих тазобедренных суставах посредством электрической стимуляции больших и средних ягодичных мышц. Данную коррекцию целесообразно сочетать со вспомогательными коррекциями, а именно с коррекцией тыльного сгибания в голеностопном суставе посредством электрической стимуляции передней большеберцовой мышцы. Основными объектами коррекции
\end{abstract}

(c) Витензон А.С., Петрушанская К.А., Гриценко Г.П., Шалыгин В.С., Сутченков И.А., 2016

Витензон Анатолий Самойлович, Москва

Петрушанская Кира Анатольевна, к.б.н., заведующая лабораторией движения, Москва

Гриценко Галина Павловна, к.т.н., в.н.с., Москва

Шалыгин Валерий Семенович, генеральный директор, Москва

Сутченков Игорь Анатольевич, инженер, Москва 
у детей с гемипаретической формой ДЦП старше 10 лет является разгибание и отведение в тазобедренном суставе и тыльное сгибание в голеностопном суставе только на паретичной нижней конечности. С нашей точки зрения, такой диффреренцированный подход должен распространяться не только на метод фазовой электрической стимуляции мышц при ходьбе, но и на другие методы восстановления двигательных функций у детей с гемипаретической фрормой ДЦП разного возраста.

Ключевые слова: гемипаретическая фрорма детского церебрального паралича, биомеханическая и иннервационная структура ходьбы, фразовая электрическая стимуляция мышц.

\section{ВВеДЕНИЕ}

В последние годы появляется ряд фундаментальных исследований, дающих комплексное биомеханическое и электромиографическое обоснование хирургической коррекции позы и ходьбы у больных детским церебральным параличом (ДЦП). Такой повышенный интерес к проблеме локомоторных нарушений у этой группы больных не является случайным, так как данные о структуре ходьбы - исходные предпосылки для разработки различных аспектов реабилитации. Биомеханическая и иннервационная структура ходьбы при спастической диплегии (форма детского церебрального паралича, при которой наблюдаются двусторонние двигательные нарушения одноименных частей тела) изучена достаточно подробно в связи с тем, что данная форма заболевания является самой распространенной и наиболее перспективной в плане восстановления нарушенных двигательных функций $[3,8-18]$. В то же время имеются лишь отдельные публикации, посвященные исследованиям биомеханических и электромиографических параметров ходьбы у детей с гемипаретической формой ДЦП (форма детского церебрального паралича, при которой двигательные расстройства менее выражены в одноименной части тела) $[10,15,16]$. В последние 15-20 лет появились работы, посвященные комплексной реабилитации этого контингента посредством сочетания фазовой электрической стимуляции мышц с другими методами восстановительного лечения: с введением инъекций ботулотоксина А [17], с лечебной гимнастикой [8, 16], с ортезированием [18]. Именно поэтому консервативное лечение больных с данной патологией также требует глубокого изучения биомеханических и электромиографических параметров ходьбы.

Необходимо отметить, что многие авторы, занимающиеся проблемой реабилитации детей с гемипаретической формой ДЦП, а также изучением биомеханической структуры ходьбы при данном заболевании, обращают основное внимание на сторону поражения и именно по этому признаку делят больных на две группы: с правосторонним и левосторонним поражением $[8,10,15-18]$. В частности, ряд иностранных авторов проводит исследования реабилитации только пораженной нижней конечности и только у больных с эквинусом (стопа согнута по направлению к подошве) в голеностопном суставе $[16,18]$. Такой подход, с одной стороны, значительно ограничивает контингент детей, нуждающихся в восстановлении двигательных функций, а с другой стороны, позволяет разработать жесткие стандарты в аспекте реабилитации, так как дети имеют практически одинаковое поражение. Эти авторы создали также и жесткий стандарт реализации фазовой электрической стимуляции мышц при ходьбе, а именно принципы выбора корректируемых движений и стимулируемых мышц, определение амплитудной и временно́й программ фазовой электрической стимуляции и сроков реабилитации. Тем не менее они резко ограничили не только контингент больных, но и объем необходимых исследований. В частности, Lee и соавторы полагают, 
что нет необходимости исследовать угловые перемещения в суставах сохранившейся нижней конечности, а также движения в тазобедренном суставе на более пораженной ноге [18]. Кроме того, они исследуют функцию только двух мышц - передней большеберцовой и внутренней икроножной. С точки зрения авторов, двигательный акт, тем более такой сложный, как ходьба, требует комплексного изучения, которое включает в себя детальное исследование основных, временных, кинематических, динамических, электромиографических и энергетических параметров ходьбы, причем исследования необходимо проводить на обеих ногах, даже при одностороннем характере поражения [2-7].

Как уже было сказано выше, большинство авторов обращают основное внимание на сторону поражения у детей с гемипаретической формой ДЦП. Между тем наши биомеханические и электромиографические исследования показывают, что сторона поражения не играет особой роли в изменении биомеханической картины ходьбы. В то же время возраст детей имеет первостепенное значение не только в диагностическом плане, но и при выборе методов и средств реабилитации.

Целью данной работы явилось биомеханическое и нейрофизиологическое обоснование применения фазовой электрической стимуляции мышц у детей с гемипаретической формой ДЦП.

\section{МАТЕРИАЛЫ И МЕТОДЫ ИССЛЕДОВАНИЯ}

Объектом изучения являлись 30 здоровых детей и 25 детей с гемипаретической формой ДЦП.

В исследование были включены две группы детей с гемипаретической формой ДЦП разного возраста: І группу составили дети 8-10 лет (13 больных), вторую группу дети 13-14 лет (12 больных). Параметры ходьбы больных детей были сопоставлены с аналогичными параметрами ходьбы здоровых детей разного возраста: от 8 до 10 лет (15 детей) и от 13 до 14 лет (15 детей).

Посредством диагностического инструментального комплекса исследовали следующие биомеханические параметры ходьбы: основные, временные, кинематические и динамические [2-6].

Основные и временные параметры регистрировали с помощью подографической методики при ходьбе испытуемых в специальных сандалях по горизонтальной дорожке, покрытой металлической лентой. Одновременно записывали подограмму обеих ног.

По подограмме определяли длительность цикла, темп ходьбы, среднюю длину шага расчетным путем, продолжительность опорной, переносной и двуопорной фаз, интервалов опоры на пятку, всю стопу и ее передний отдел, интервал $\tau$ (время от момента окончания опоры на всю стопу одной ноги до начала опоры другой ноги), коэффициент ритмичности (отношение длительности переносных фаз обеих ног).

Кинематические параметры ходьбы (угловые перемещения в голеностопном, коленном и тазобедренном суставах обеих нижних конечностей) регистрировали посредством многозвенных электрогониометров.

Динамические параметры ходьбы (вертикальную $R_{z}$, продольную $R_{x}$ и поперечную $R_{y}$ составляющие главного вектора опорной реакции) исследовали посредством динамографической методики.

Электрическую активность мышц при ходьбе изучали с помощью компьютерной электромиографической методики, состоящей из усилителя биопотенциалов УБФ-4 с устройством, позволяющим ввод в аналого-цифровой преобразователь не натуральной электромиограммы, а ее огибающей при очень малой постоянной времени (5 мс), персонального компьютера и программного обеспечения 
для ввода и обработки результатов измерения. Калибровку установки осуществляли посредством синусоидального сигнала частотой 200 Гц от звукового генератора ЗГ-10.

Для отведения электрической активности мышц использовали биполярные накожные электроды, изготовленные из латуни в виде плоских чашечек, заполняемых электропроводной пастой.

С учетом возрастных параметров мышц применяли два вида электродов: для детей 8-10 лет диаметр электродов был равен 7,5 мм, а постоянное межэлектродное расстояние - 20 мм, для детей 13 лет диаметр электродов равнялся 10 мм, а межэлектродное расстояние - 40 мм.

Электроды помещали над мышечным брюшком в двигательной области и фиксировали на коже полосками лейкопластыря и эластичным бинтом.

Измеряемые параметры обрабатывали с частотой 200 раз в секунду при помощи 12-разрядного аналого-цифрового преобразователя с погрешностью 1-2 разряда программой съема измерений. Эта программа читает данные на выходе аналогоцифрового преобразователя, оцифровывает их с частотой 200 раз в секунду и записывает на жесткий диск в виде файлов для длительного хранения. Объектом исследования была электрическая активность 10 симметричных мышц нижних конечностей и туловища (передней большеберцовой, внутренней икроножной, наружной широкой, полусухожильной, прямой бедра, двуглавой бедра, большой и средней ягодичных, длинной приводящей и крестцово-остистой). В результате исследований были получены усредненные графики распределения электрической активности мышц в течение цикла ходьбы (профиль электромиограммы) и ряд количественных электромиографических показателей (средняя электрическая активность, суммарный интеграл и суммарный интеграл за 10 м пути).

В то же время временные, кинематические, динамические и электромиографические параметры, информируя об отдельных событиях в течение двигательного цикла, не позволяют получить целостное представление об изменении акта ходьбы. Между тем анализ профилограмм моментов мышечных сил дает весьма четкое представление о направленности процессов в связи с относительной простотой фазовой структуры моментов и однозначностью изменений при усилении или ослаблении локомоторных расстройств. На основании данных биомеханических исследований посредством метода математического моделирования были получены развертки (профилограммы) моментов мышечных сил в суставах нижних конечностей. У здоровых детей исследовали моменты мышечных сил при ходьбе с различной скоростью, у больных - до и после курса фазовой электрической стимуляции [4-6].

В настоящем исследовании этот метод был использован для получения сравнительной оценки тяжести нарушений у двух групп детей с гемипаретической формой ДЦП, а также для отслеживания результатов восстановительного лечения посредством фазовой электрической стимуляции мышц.

Как уже было сказано выше, большинство авторов, занимающихся реабилитацией детей с гемипаретической формой ДЦП, сопоставляют биомеханические и электромиографические параметры их ходьбы с соответствующими параметрами здоровых детей без учета возраста, т.е. все здоровые дети составляют одну группу [11-15]. В то же время все биомеханические и электромиографические параметры ходьбы у детей имеют четкие возрастные особенности. В связи с этим считаем необходимым дать краткую характеристику особенностей ходьбы здоровых детей разного возраста. 


\section{ОСОБЕННОСТИ БИОМЕХАНИЧЕСКОЙ И ИННЕРВАЦИОННОЙ СТРУКТУРЫ ХОДЬБЫ ЗДОРОВЫХ ДЕТЕЙ РАЗНОГО ВОЗРАСТА}

Как показали наши многопрофильные комплексные исследования ходьбы здоровых детей разного возраста, биомеханическая структура локомоторного акта практически полностью сформирована к возрасту 7 лет [5]. Основное отличие ходьбы детей от взрослой нормы заключается в более высоком темпе передвижения, уменьшении длины шага и средней скорости локомоции. Даже здоровым детям, особенно в младшем школьном возрасте, свойственна некоторая асимметрия движений, наклонность к легкой сгибательной позиции нижних конечностей в опорной фазе, уменьшение моментов мышечных сил, формирующих задний толчок, бо́льшая крутизна переднего и заднего фронтов кривых вертикальной $R_{z}$ составляющей опорной реакции.

Дальнейшие исследования позволили нам не только выявить особенности биомеханической структуры ходьбы, но и определить профиль электромиограммы мышц у здоровых детей. Иннервационный стереотип локомоции, близкий к взрослой норме, формируется к возрасту 13 лет. По сравнению со взрослыми профиль электромиограммы у детей 8-10 лет характеризуется меньшей отчетливостью максимумов электрической активности, их бо́льшей длительностью и пролонгированием на соседние фазы шага. Становление иннервационного стереотипа ходьбы у детей школьного возраста происходит через снижение промежуточной межпиковой активности, увеличение амплитуды и уменьшение длительности максимумов активности, что ведет к концентрации мышечных усилий в более узкие интервалы времени, обеспечивая тем самым оптимальный баллистический характер локомоторных движений. Причем с увеличением возраста не только складывается более четкий иннервационный стереотип локомоции, но и снижается ее энергетическая стоимость, уменьшаются средняя и максимальная электрическая активность мышц в течение цикла ходьбы.

Именно поэтому биомеханические и электромиографические параметры ходьбы детей с гемипаретической формой ДЦП были сопоставлены с соответствующими параметрами здоровых детей такого же возраста.

\section{КЛИНИЧЕСКАЯ КАРТИНА ХОДЬБЫ ДЕТЕЙ С ГЕМИПАРЕТИЧЕСКОЙ ФОРМОЙ ДЦП}

Для детей с гемипаретической формой ДЦП характерен парез мышцразгибателей и спастичность мышц-сгибателей верхней конечности и, наоборот, спастичность мышц-разгибателей (четырехглавой мышцы бедра и трехглавой мышцы голени) и слабость мышц-сгибателей нижней конечности.

Дети обеих групп с гемипаретической формой ДЦП могли ходить самостоятельно. При ходьбе у них отмечался эквинус в голеностопном суставе наряду с уменьшением амплитуды движений в коленном и тазобедренном суставах на пораженной конечности. Кроме того, наблюдались асимметричные колебания туловища относительно фронтальной плоскости. Паретичная рука, приведенная к туловищу и согнутая в локтевом, лучезапястном суставах и кисти, практически не принимала участия в локомоторном акте.

\section{БИОМЕХАНИЧЕСКАЯ И ИННЕРВАЦИОННАЯ СТРУКТУРА ХОДЬБЫ ДЕТЕЙ С ГЕМИПАРЕТИЧЕСКОЙ ФОРМОЙ ДЦП}

Клиническая картина ходьбы детей с гемипаретической формой ДЦП была уточнена посредством биомеханических и электромиографических исследований. 
В табл. 1 представлены основные параметры ходьбы здоровых детей и детей с гемипаретической формой ДЦП. Из этих данных следует, что у детей обеих групп с гемипаретической формой ДЦП наблюдается ухудшение основных показателей ходьбы. У больных первой группы темп ходьбы снижается на 13\% (103 шага в минуту), длина двойного шага редуцируется на $19 \%(0,88$ м), а средняя скорость передвижения сокращается на $30 \%$ (2,7 км/ч). Ходьба больных второй группы характеризуется более низким темпом (94 шага в минту), но бо́льшей длиной шага и скоростью ходьбы, соответственно 1,04 м и 3 км/ч.

У всех больных отмечается также резкое нарушение временно́й структуры ходьбы (табл. 2, 3). Для обеих групп детей характерно увеличение длительности опорной фазы и уменьшение длительности переносной фазы, однако на менее

Таблииа 1

Основные параметры ходьбы здоровых детей и детей с гемипаретической формой ДЦП

\begin{tabular}{|c|c|c|c|c|c|c|c|c|}
\hline & \multicolumn{2}{|c|}{ Первая группа } & \multicolumn{6}{c|}{ Вторая группа } \\
\cline { 2 - 10 } Параметр & $\begin{array}{c}\text { 3доровые } \\
\text { дети } \\
8-10 \text { лет } \\
(n=15)\end{array}$ & $\begin{array}{c}\text { Дети } \\
\text { с ДЦП } \\
\text { І групп } \\
(n=13)\end{array}$ & \multicolumn{3}{|c|}{$\begin{array}{c}\text { 3доровые дети 13-14 лет } \\
(n=15)\end{array}$} & \multicolumn{3}{|c|}{ Дети с ДЦП ІІ группы } \\
\cline { 2 - 10 } & $M \pm m$ & $M \pm m$ & $M \pm m$ & $\begin{array}{c}\% \text { к } \\
\text { норме }\end{array}$ & $p$ & $M \pm m$ & $\begin{array}{c}\% \text { к } \\
\text { норме }\end{array}$ & $p$ \\
\hline $\begin{array}{c}\text { Длительность } \\
\text { цикла, с }\end{array}$ & $1,01 \pm 0,01$ & $1,17 \pm 0,03$ & $1,13 \pm 0,03$ & 116 & $<0,05$ & $1,27 \pm 0,06$ & 112 & $<0,05$ \\
\hline $\begin{array}{c}\text { Длина } \\
\text { двойного } \\
\text { шага, м }\end{array}$ & $1,09 \pm 0,02$ & $0,88 \pm 0,06$ & $1,26 \pm 0,04$ & 81 & $<0,05$ & $1,04 \pm 0,05$ & 83 & $<0,05$ \\
\hline $\begin{array}{c}\text { Скорость } \\
\text { ходьбы, } \\
\text { км/ч }\end{array}$ & $3,89 \pm 0,07$ & $2,70 \pm 0,22$ & $4,03 \pm 0,11$ & 69 & $<0,05$ & $2,95 \pm 0,14$ & 73 & $<0,05$ \\
\hline $\begin{array}{c}\text { Темп } \\
\text { ходьбы, } \\
\text { шаг/мин }\end{array}$ & $119 \pm 1$ & $103 \pm 3$ & $106 \pm 2$ & 87 & $<0,05$ & $94 \pm 3$ & 89 & $<0,05$ \\
\hline
\end{tabular}

Временные параметры ходьбы здоровых детей 8-10 лет (\% T)

и детей с гемипаретической формой ДЦП (первая группа)

\begin{tabular}{|c|c|c|c|c|c|c|c|}
\hline & $\begin{array}{c}\text { 3доровые } \\
\text { дети } \\
(n=15)\end{array}$ & \multicolumn{6}{|c|}{ Дети с ДЦП $(n=13)$} \\
\cline { 3 - 8 } Параметр & $M \pm m$ & $M \pm m$ & $\begin{array}{c}\text { Более пораженная нижняя } \\
\text { норме }\end{array}$ & $p$ & \multicolumn{3}{|c|}{$\begin{array}{c}\text { Менее пораженная } \\
\text { нижняя конечность }\end{array}$} \\
\cline { 4 - 8 } & $M \pm m$ & $\begin{array}{c}\% \text { к } \\
\text { норме }\end{array}$ & $p$ \\
\hline $\begin{array}{c}\text { Длительность опоры } \\
\text { на пятку }\end{array}$ & $10,7 \pm 0,5$ & $2,8 \pm 0,7$ & 26 & $<0,05$ & $4,7 \pm 0,6$ & 44 & $<0,05$ \\
\hline $\begin{array}{c}\text { Длительность опоры } \\
\text { на всю стопу }\end{array}$ & $33,2 \pm 1,3$ & $26,3 \pm 1,5$ & 79 & $<0,05$ & $40,0 \pm 1,4$ & 120 & $<0,05$ \\
\hline $\begin{array}{c}\text { Длительность опоры } \\
\text { на носок }\end{array}$ & $17,3 \pm 1,1$ & $35,3 \pm 1,3$ & 204 & $<0,05$ & $23,9 \pm 1,2$ & 138 & $<0,05$ \\
\hline $\begin{array}{c}\text { Длительность } \\
\text { переносной фазы }\end{array}$ & $38,8 \pm 0,6$ & $35,6 \pm 0,9$ & 92 & $<0,05$ & $31,4 \pm 0,8$ & 81 & $<0,05$ \\
\hline $\begin{array}{c}\text { Длительность } \\
\text { двуопорной фазы }\end{array}$ & $11,2 \pm 0,7$ & $16,7 \pm 1,1$ & 149 & $<0,05$ & $16,3 \pm 0,9$ & 146 & $<0,05$ \\
\hline Интервал $\tau$ & $6,1 \pm 1,4$ & $19,0 \pm 1,7$ & 311 & $<0,05$ & $7,2 \pm 1,5$ & 118 & $>0,05$ \\
\hline
\end{tabular}


пораженной ноге эта тенденция выражена в бо́льшей степени. Также происходит перефазировка внутри опорной фазы: значительно увеличен интервал опоры на носок на обеих ногах. Как правило, такая перефазировка связана с эквинусной деформацией или, чаще, с эквинусной установкой стопы. На обеих ногах возрастает продолжительность двуопорной фазы, что указывает на значительное снижение статической устойчивости при ходьбе. Интервал $\tau$ значительно выше нормы, что связано с удлинением интервала опоры на носок.

Более детальное сопоставление кинематики суставов при ходьбе здоровых детей и детей с гемипаретической формой ДЦП показывает следующее (рис. 1, 2).

Кривая голеностопного сустава при ходьбе здоровых детей дает четыре экстремальных значения, из которых два соответствуют подошвенному сгибанию в суставе в начале и в конце опорной фазы, а два - тыльному сгибанию во время переката через носок и в первой половине переносной фазы. У обеих групп детей с гемипаретической формой ДЦП наибольшие изменения отмечаются при движениях в голеностопных суставах. Это, прежде всего, связано с эквинусным положением в голеностопном суставе, что проявляется в смещении кривой вниз относительно нулевой линии в начале локомоторного цикла. При этом первое тыльное сгибание резко снижено, особенно у больных первой группы. Также редуцировано второе подошвенное сгибание на более пораженной ноге, что указывает на слабость отталкивания стопы от опорной поверхности. Второе тыльное сгибание отсутствует.

Кривая коленного угла при ходьбе здоровых детей состоит из двух полуволн: с малой и большой амплитудой. Первая из них характеризует подгибание в коленном суставе, имеющее главным образом амортизационное значение. За каждым сгибанием следует практически полное разгибание.

Временные параметры ходьбы здоровых детей 13-14 лет (\% T)

Таблииа 3 и детей с гемипаретической формой ДЦП (вторая группа)

\begin{tabular}{|c|c|c|c|c|c|c|c|}
\hline \multirow{3}{*}{ Параметр } & \multirow{3}{*}{$\begin{array}{c}\begin{array}{c}\text { Здоровые } \\
\text { дети } \\
(n=15)\end{array} \\
M \pm m\end{array}$} & \multicolumn{6}{|c|}{ Дети с ДЦП (n= 12) } \\
\hline & & \multicolumn{3}{|c|}{$\begin{array}{c}\text { Более пораженная } \\
\text { нижняя конечность }\end{array}$} & \multicolumn{3}{|c|}{$\begin{array}{l}\text { Менее пораженная } \\
\text { нижняя конечность }\end{array}$} \\
\hline & & $M \pm m$ & $\begin{array}{c}\% \text { к } \\
\text { норме }\end{array}$ & $p$ & $M \pm m$ & $\begin{array}{c}\% \text { к } \\
\text { норме }\end{array}$ & $p$ \\
\hline $\begin{array}{c}\text { Длительность опоры } \\
\text { на пятку }\end{array}$ & $7,5 \pm 0,6$ & $3,0 \pm 0,7$ & 40 & $<0,05$ & $6,5 \pm 0,6$ & 87 & $>0,05$ \\
\hline $\begin{array}{c}\text { Длительность опоры } \\
\text { на стопу }\end{array}$ & $36,6 \pm 2,1$ & $35,9 \pm 2,4$ & 98 & $>0,05$ & $40,2 \pm 2,2$ & 110 & $>0,05$ \\
\hline $\begin{array}{c}\text { Длительность опоры } \\
\text { на носок }\end{array}$ & $19,2 \pm 1,8$ & $26,7 \pm 2,1$ & 139 & $<0,05$ & $21,9 \pm 1,9$ & 114 & $>0,05$ \\
\hline $\begin{array}{c}\text { Длительность } \\
\text { переносной фазы }\end{array}$ & $36,7 \pm 0,6$ & $34,4 \pm 0,9$ & 94 & $<0,05$ & $31,4 \pm 0,8$ & 86 & $<0,05$ \\
\hline $\begin{array}{c}\text { Длительность } \\
\text { двуопорной фазы }\end{array}$ & $13,3 \pm 0,4$ & $15,4 \pm 1,1$ & 116 & $>0,05$ & $18,8 \pm 0,9$ & 141 & $<0,05$ \\
\hline Интервал $\tau$ & $5,9 \pm 1,2$ & $7,9 \pm 1,3$ & 134 & $>0,05$ & $6,5 \pm 0,8$ & 110 & $>0,05$ \\
\hline
\end{tabular}


Более пораженная нижняя конечность
Менее пораженная нижняя конечность
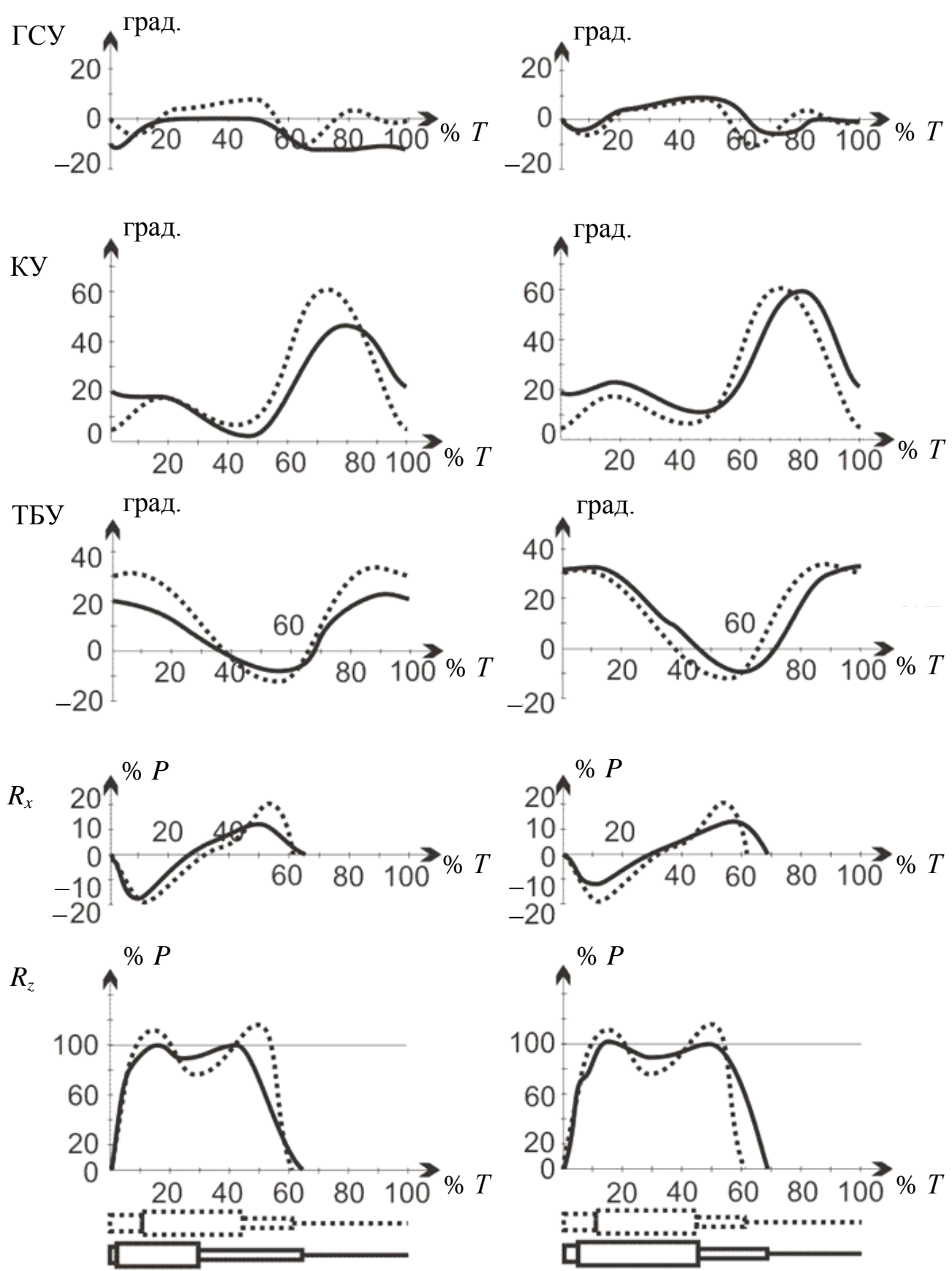

Рис. 1. Кинематические и динамические параметры ходьбы здоровых детей 8-10 лет и детей первой группы с гемипаретической формой ДЦП: ГСУ голеностопный угол; КУ - коленный угол; ТБУ - тазобедренный угол; $R_{z}-$ вертикальная составляющая опорной реакции; $R_{x}$ - продольная составляющая опорной реакции; $P$ - вес тела; $T$ - цикл шага. Пунктирная линия - ходьба в норме, сплошная линия - больные

У детей первой группы отмечается увеличение подгибания (сгибания в опорную фазу) и снижение основного сгибания в переносную фазу на паретичной ноге. На сохранившейся ноге амплитуда сгибания в опорную фазу увеличена, отмечается незначительная сгибательная позиция в коленном суставе. В то же время амплитуда 
основного сгибания близка к возрастной норме. У многих больных отмечается рекурвация (избыточное разгибание) в коленном суставе, что проявляется в уменьшении амплитуды разгибания ниже уровня нулевой линии.

У второй группы больных наблюдается большая асимметрия движений в коленном суставе по сравнению с первой группой. При этом на паретичной нижней конечности снижается амплитуда как подгибания, так и основного сгибания

\author{
Более пораженная нижняя Менее пораженная нижняя \\ конечность \\ конечность
}
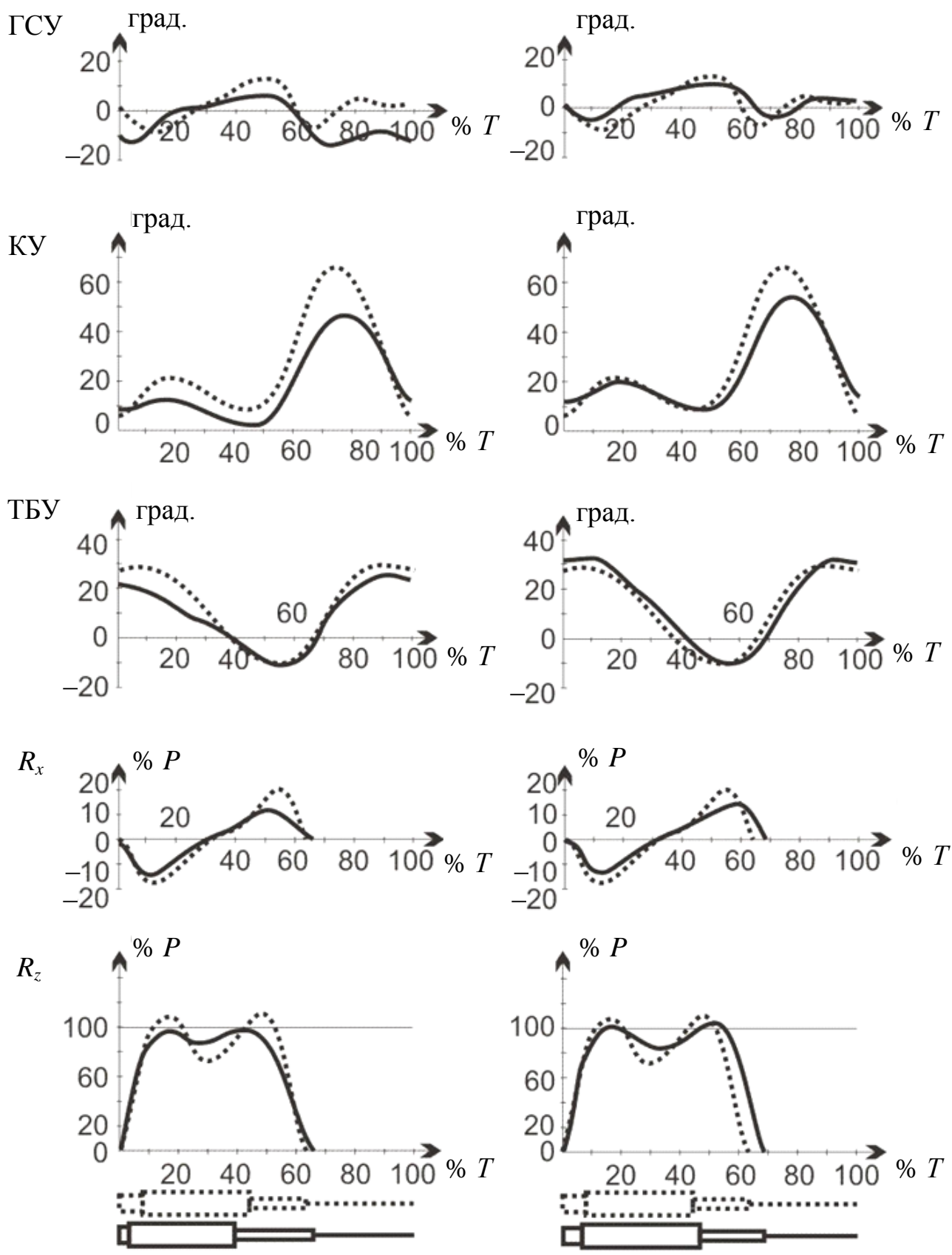

Рис. 2. Кинематические и динамические параметры ходьбы здоровых детей 13-14 лет и детей второй группы с гемипаретической формой ДЦП. Остальные обозначения те же, что на рис. 1 
в переносную фазу. На сохранившейся конечности незначительно снижается амплитуда только основного сгибания.

Кривая тазобедренного угла при ходьбе здоровых детей имеет три экстремальных значения; два из них соответствуют сгибанию в суставе, а одно разгибанию. Каждый цикл начинается со сгибания, которое удерживается в течение интервала опоры на пятку, затем происходит разгибание в суставе, достигающее максимального значения в середине интервала опоры на носок, затем снова наступает сгибание в переносную фазу, которое лишь в конце сменяется небольшим разгибанием.

У обеих групп детей с гемипаретической формой ДЦП отмечаются незначительные изменения при движениях в тазобедренных суставах. Тем не менее на паретичной конечности происходит уменьшение амплитуды преимущественно за счет снижения величины угла сгибания как в опорную, так и в переносную фазу.

Исследование динамических параметров ходьбы у детей с гемипаретической формой ДЦП выявляет их существенные отличия от соответствующих параметров у здоровых детей (см. рис. 1, 2). Вертикальная составляющая опорной реакции (кривая $R_{z}$ ) у здоровых детей 8-13 лет имеет двугорбый вид с четко выраженными передним, задним толчками и минимумом между ними.

Продольная составляющая опорной реакции (кривая $R_{x}$ ) в том же возрастном диапазоне представлена двумя противоположно направленными максимумами, из которых отрицательный максимум соответствует переднему толчку, а положительный - заднему.

У больных первой группы с двух сторон отмечается примерно одинаковое снижение амплитуды переднего и заднего толчков вертикальной составляющей $R_{z}$ опорной реакции. В то же время в кривой продольной составляющей $R_{x}$ наблюдается определенная асимметрия: на более пораженной конечности возрастает амплитуда переднего толчка и значительно уменьшается амплитуда заднего толчка.

У больных второй группы сохраняется такая же тенденция снижения амплитуды экстремумов составляющих опорной реакции, однако у детей старшего возраста уже заметна четкая асимметрия динамических параметров ходьбы. При значительном эквинусе в голеностопном отмечается возрастание переднего толчка и уменьшение величины заднего толчка в кривой $R_{z}$ паретичной конечности. Последнее обусловлено ограничением силовых возможностей трехглавой мышцы голени, фиксированной в спастической контрактуре (ограничением амплитуды пассивных движений в суставе).

Однако наиболее информативным параметром являются моменты мышечных сил в суставах нижних конечностей (рис. 3, 4). У здоровых детей кривые моментов мышечных сил в тазобедренном и коленном суставах содержат две основные фазы, тогда как в голеностопном суставе наблюдается только одна. Первая фаза моментов в тазобедренном и коленном суставах при произвольном темпе ходьбы здоровых детей 8-13 лет занимает две начальные трети опорной фазы. Данная фаза является отрицательной, ее экстремум проецируется на $t=14-15 \%$ временной оси. Данная фаза отражает деятельность мышц-разгибателей тазобедренного и коленного суставов, которые, с одной стороны, обеспечивают опорность нижней конечности, а с другой подъем общего центра масс до наивысшего положения.

Вторая фаза моментов в тазобедренном и коленном суставах располагается в последней трети опорной фазы; ее положительный экстремум приходится на $t=56 \%$ цикла. Моменты мышечных сил в этой фазе направлены на отталкивание ноги от опорной поверхности, что обусловлено главным образом деятельностью трехглавой мышцы голени и мышц-сгибателей коленного сустава. 
Более пораженная нижняя конечность
Менее пораженная нижняя конечность
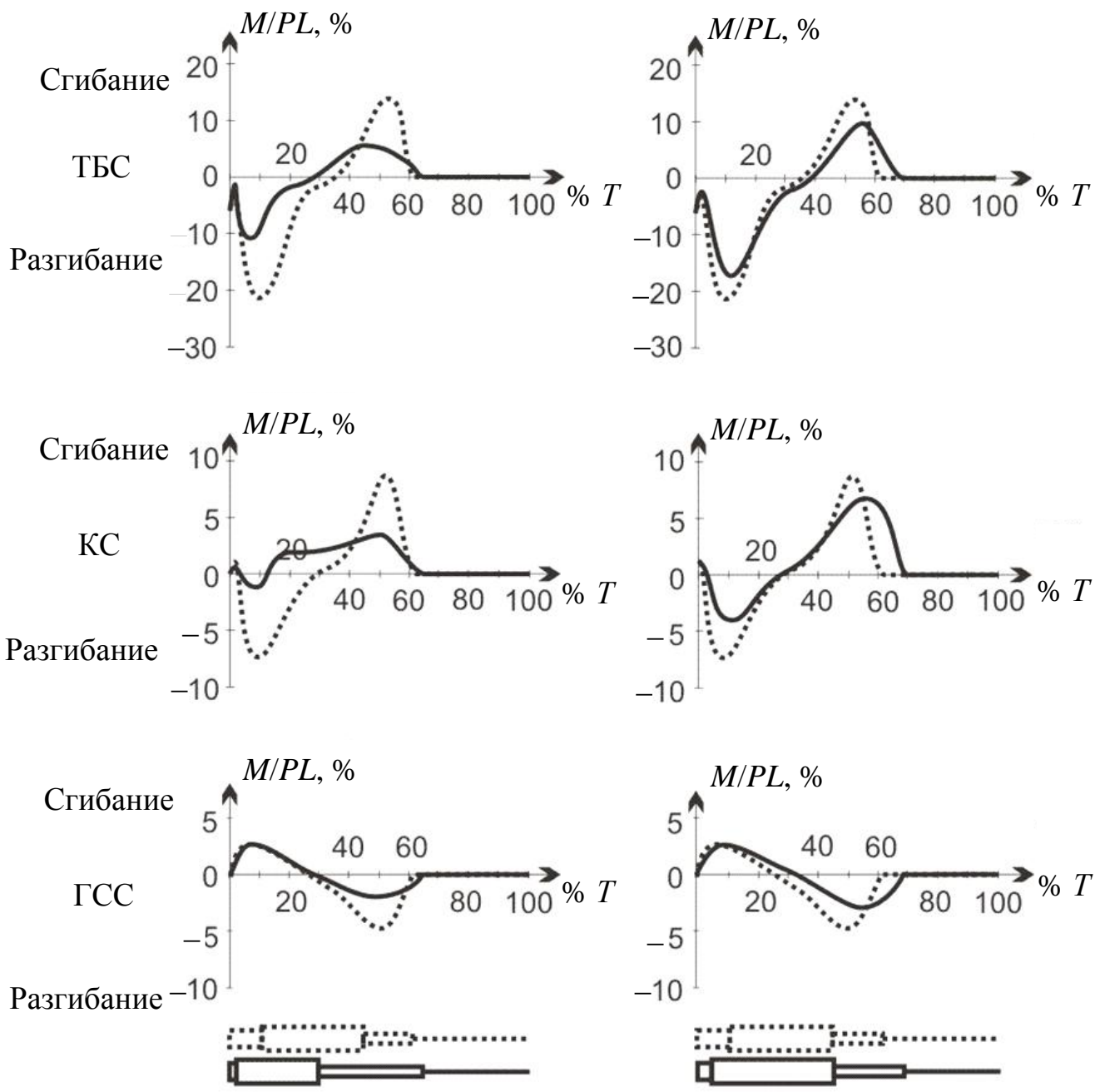

Рис. 3. Моменты мышечных сил $M(\%$ к весу тела $P$ и росту $L)$ в суставах нижних конечностей здоровых детей 8-10 лет и детей первой группы с гемипаретической формой ДЦП: ТБС - тазобедренный сустав; КС - коленный сустав; ГСС голеностопный сустав

В голеностопном суставе кривая момента мышечных сил образует одну фазу продолжительностью в 50 \% цикла. Величина моментов мышечных сил неодинакова для разных сочленений нижних конечностей: наибольшие моменты возникают в тазобедренном суставе, значительно меньшие - в коленном суставе, еще меньшие в голеностопном.

Для первой группы детей с гемипаретической формой ДЦП типично существенное уменьшение амплитуды моментов мышечных сил в обе фазы - переднего и заднего толчков. Обращает на себя внимание, что первая фаза в тазобедренном и коленном суставах резко укорочена, в то время как вторая фаза значительно пролонгирована. Отмечаются приблизительно равномерное снижение амплитуды и длительности переднего и заднего толчков на более пораженной нижней конечности и незначительные изменения этих параметров на менее пораженной ноге. Асимметрия моментов мышечных сил более выражена у больных второй группы. У этих детей наблюдается уменьшение моментов мышечных сил в фазы переднего и заднего толчка на паретичной ноге и их незначительное изменение на более сохранившейся ноге. 
Более пораженная нижняя конечность
Менее пораженная нижняя конечность
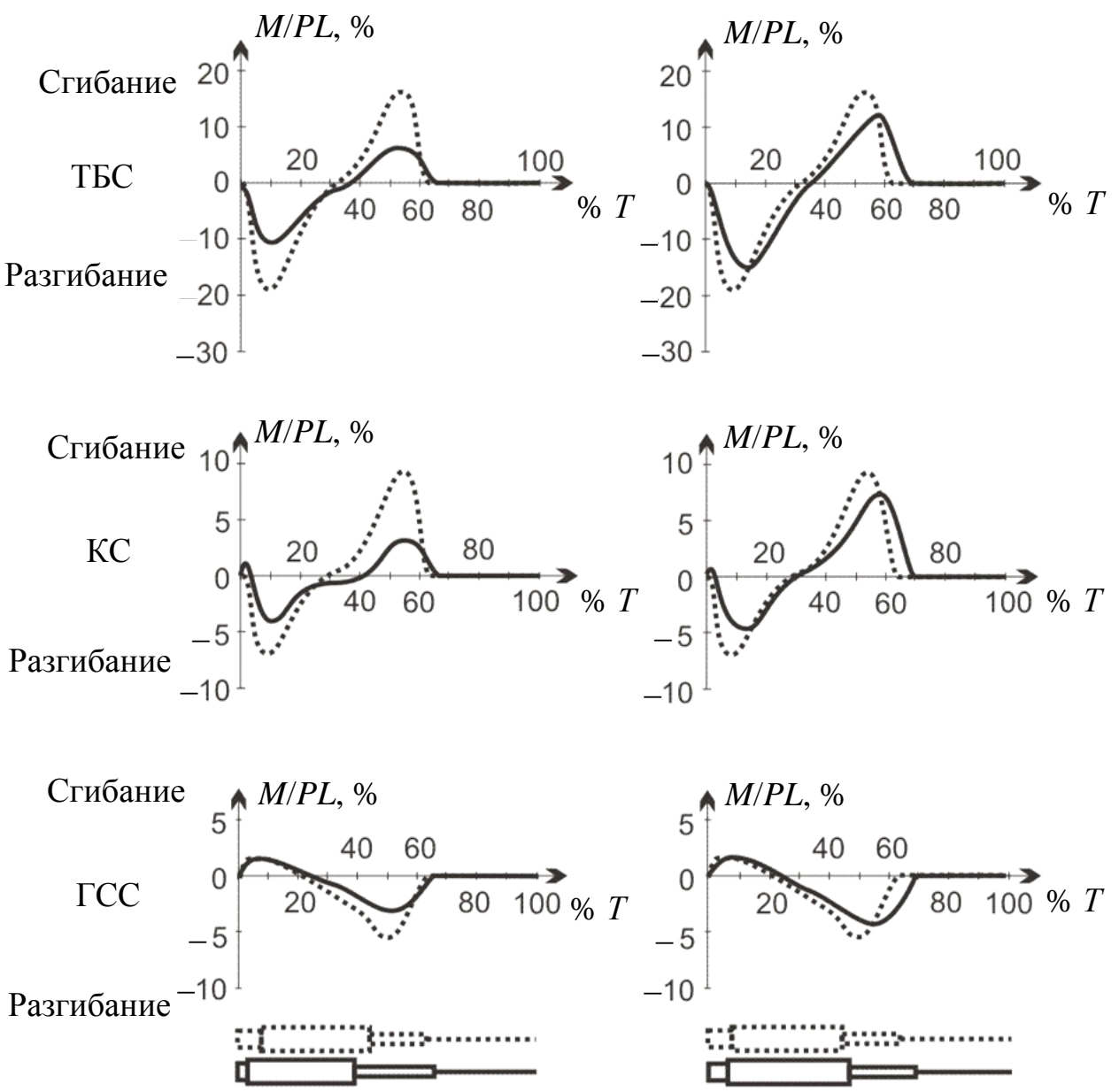

Рис. 4. Моменты мышечных сил $M(\%$ к весу тела $P$ и росту $L)$ в суставах нижних конечностей здоровых детей 13-14 лет и детей второй группы с гемипаретической формой ДЦП: ТБС - тазобедренный сустав; КС - коленный сустав; ГСС голеностопный сустав

Тем не менее у детей обеих групп с гемипаретической формой ДЦЦ амплитудные значения моментов мышечных сил в голеностопном суставе значительно ниже, чем у здоровых детей такого же возраста.

\section{Профиль электромиограммы мышц нижних конечностей}

Наибольший интерес представляют данные исследования электрической активности мышц в течение локомоторного цикла (рис. 5, 6), которые показали, что для больных первой группы характерно значительное снижение максимумов электрической активности мышц голени (передней большеберцовой и икроножной) обеих нижних конечностей, причем на стороне пареза отмечалось полное нивелирование максимумов активности передней большеберцовой мышцы. Максимумы активности икроножных мышц уменьшаются по величине, но увеличиваются по длительности. Еще в бо́льшей степени данная тенденция отмечается на менее пораженной конечности, где максимум активности икроножной мышцы перемещается в среднюю треть опорной фазы в связи с перемещением вертикальной нагрузки. На менее пораженной ноге также наблюдается снижение максимумов активности передней большеберцовой мышцы, причем как в начале опорной фазы, 
Более пораженная нижняя конечность
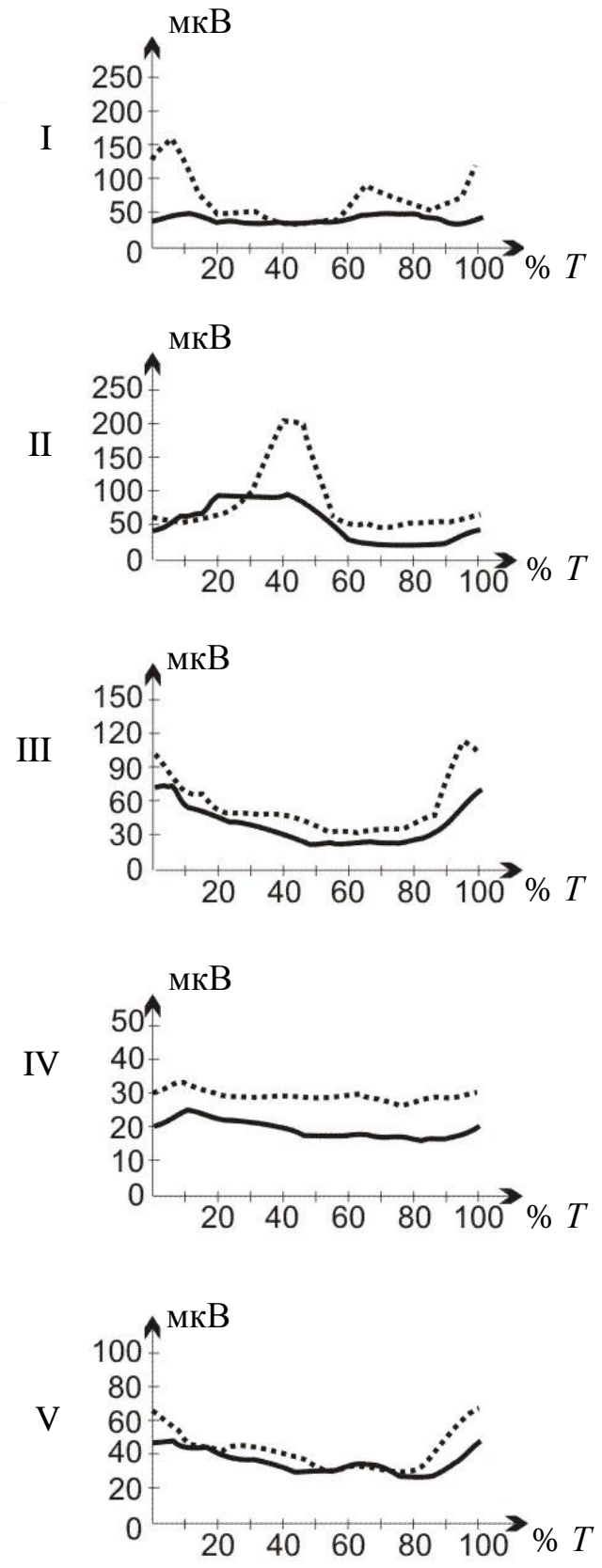

Менее пораженная нижняя конечность
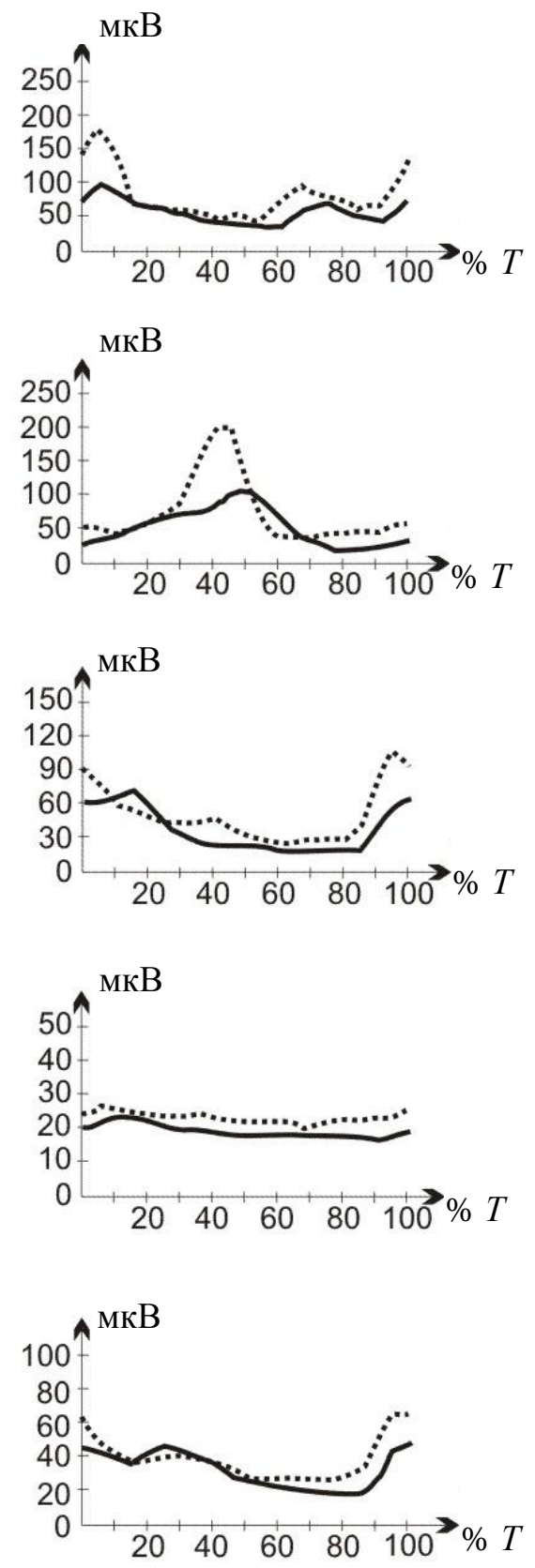

Рис. 5. Электрическая активность мышц нижних конечностей в течение локомоторного цикла у здоровых детей 8-10 лет и детей первой группы с гемипаретической формой ДЦП: I - передняя большеберцовая мышца, II икроножная мышца, III - полусухожильная мышца, IV - большая ягодичная мышца, V - двуглавая мышца бедра

так и в ее конце. Такое же симметричное поражение отмечается на мышцах бедра и таза. При этом типично уменьшение максимумов активности большинства мышц и их пролонгирование на бо́льшую часть локомоторного цикла.

Для второй группы больных характерно снижение активности мышц только на стороне пареза и повышение максимумов активности многих мышц бедра и таза с двух сторон, особенно разгибателей и абдукторов в тазобедренном суставе - двуглавой 
бедра, большой и средней ягодичных мышц. Обращает на себя внимание, что максимумы активности не только увеличиваются, но и становятся более отчетливыми. Таким образом, у второй группы больных отмечается тенденция к увеличению активности мышц проксимальных отделов ноги при поражении мышц в дистальном отделе конечности.
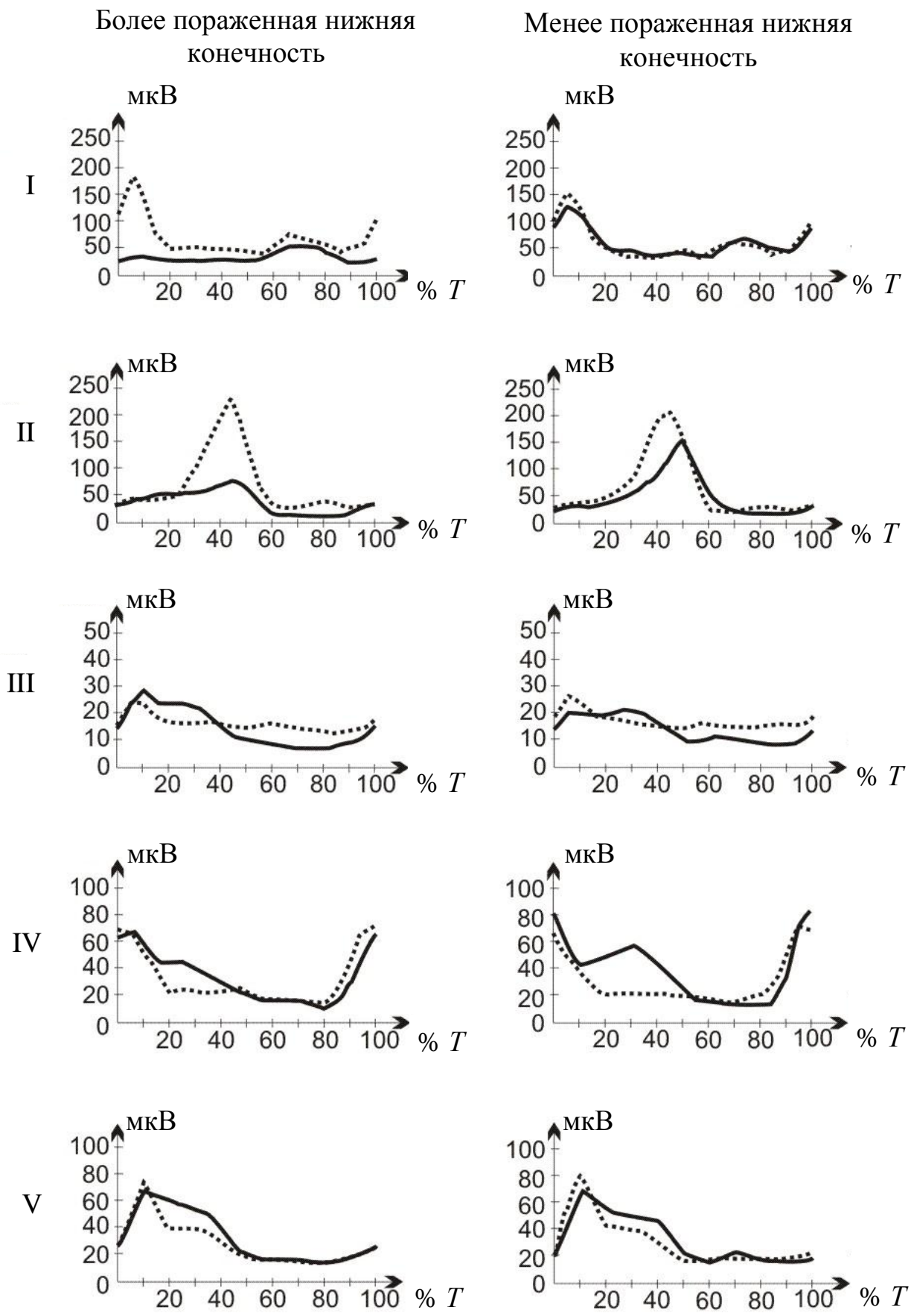

Рис. 6. Электрическая активность мышц нижних конечностей в течение локомоторного цикла у здоровых детей 13-14 лет и детей второй группы с гемипаретической формой ДЦП: I - передняя большеберцовая мышца; II икроножная мышца; III - большая ягодичная мышца; IV - двуглавая мышца бедра; $\mathrm{V}$ - средняя ягодичная 
Таблица 4

Электрическая активность мышц нижних конечностей (мкВ) при ходьбе здоровых детей 8-10 лет и детей с гемипаретической формой ДЦП (первая группа)

\begin{tabular}{|c|c|c|c|c|c|c|c|}
\hline \multirow{3}{*}{ Параметр } & \multirow{3}{*}{$\begin{array}{c}\begin{array}{c}\text { Здоровые } \\
\text { дети } \\
(n=15)\end{array} \\
M \pm m\end{array}$} & \multicolumn{6}{|c|}{ Дети с ДЦП $(n=13)$} \\
\hline & & \multicolumn{3}{|c|}{$\begin{array}{c}\text { Более пораженная } \\
\text { нижняя конечность }\end{array}$} & \multicolumn{3}{|c|}{$\begin{array}{l}\text { Менее пораженная } \\
\text { нижняя конечность }\end{array}$} \\
\hline & & $M \pm m$ & $\begin{array}{c}\% \text { к } \\
\text { норме }\end{array}$ & $p$ & $M \pm m$ & $\begin{array}{c}\% \text { к } \\
\text { норме }\end{array}$ & $p$ \\
\hline $\begin{array}{c}\text { Средняя электрическая } \\
\text { активность за цикл шага }\end{array}$ & $462 \pm 10$ & $333 \pm 11$ & 72 & $<0,05$ & $369 \pm 9$ & 80 & $<0,05$ \\
\hline $\begin{array}{l}\text { Интеграл электрической } \\
\text { активности за цикл шага }\end{array}$ & $467 \pm 13$ & $389 \pm 14$ & 83 & $<0,05$ & $432 \pm 11$ & 93 & $>0,05$ \\
\hline $\begin{array}{c}\text { Суммарный интеграл } \\
\text { за } 10 \text { м пути }\end{array}$ & $4283 \pm 119$ & $4425 \pm 136$ & 103 & $>0,05$ & $4911 \pm 123$ & 115 & $<0,05$ \\
\hline
\end{tabular}

Таблица 5

Электрическая активность мышЦ нижних конечностей (мкВ) при ходьбе здоровых детей 13-14 лет и детей с гемипаретической формой ДЦП (вторая группа)

\begin{tabular}{|c|c|c|c|c|c|c|c|}
\hline \multirow{3}{*}{ Параметр } & \multirow{3}{*}{$\begin{array}{c}\text { Здоровые } \\
\begin{array}{c}\text { дети } \\
(n=15)\end{array} \\
M \pm m\end{array}$} & \multicolumn{6}{|c|}{ Дети с ДЦП $(n=12)$} \\
\hline & & \multicolumn{3}{|c|}{$\begin{array}{c}\text { Более пораженная } \\
\text { нижняя конечность }\end{array}$} & \multicolumn{3}{|c|}{$\begin{array}{l}\text { Менее пораженная } \\
\text { нижняя конечность }\end{array}$} \\
\hline & & $M \pm m$ & $\begin{array}{c}\% \text { к } \\
\text { норме }\end{array}$ & $p$ & $M \pm m$ & $\begin{array}{c}\% \text { к } \\
\text { норме }\end{array}$ & $p$ \\
\hline $\begin{array}{c}\text { Средняя электрическая } \\
\text { активность за цикл шага }\end{array}$ & $550 \pm 8$ & $347 \pm 9$ & 63 & $<0,05$ & $446 \pm 9$ & 81 & $<0,05$ \\
\hline $\begin{array}{l}\text { Интеграл электрической } \\
\text { активности за цикл шага }\end{array}$ & $622 \pm 9$ & $440 \pm 12$ & 71 & $<0,05$ & $566 \pm 11$ & 91 & $<0,05$ \\
\hline $\begin{array}{c}\text { Суммарный интеграл } \\
\text { за } 10 \text { м пути }\end{array}$ & $4933 \pm 68$ & $4232 \pm 113$ & 86 & $<0,05$ & $5440 \pm 108$ & 110 & $<0,05$ \\
\hline
\end{tabular}

По сравнению со здоровыми пациентами у обеих групп детей с гемипаретической формой ДЦП снижаются средняя электрическая активность мышц (величина, эквивалентная мощности мышц) и суммарный интеграл (величина, эквивалентная работе мышц) за локомоторный цикл. В то же время наблюдается повышение суммарного интеграла электрической активности за 10 м пути относительно нормы, в особенности для менее пораженной конечности (табл. 4, 5).

\section{ОБСУЖДЕНИЕ РЕЗУЛЬТАТОВ}

Клинико-биомеханические и в особенности электромиографические данные демонстрируют различия биомеханической и иннервационной структуры ходьбы у двух групп детей с гемипаретической формой ДЦП. С нашей точки зрения, наибольший интерес представляет изменение профиля электромиограммы мышц у двух групп больных. Для больных первой группы характерно общее симметричное снижение активности мышц с акцентом на мышцы дистальных отделов ног. У больных второй группы парез нижних конечностей имеет отчетливый асимметричный характер. У данных пациентов оказывается сформированным более компенсированный вид гемипаретической походки, при которой дефект имеет отчетливый асимметричный 
характер и в значительной мере возмещается усилением работы мышц проксимальных отделов обеих нижних конечностей. Количественные закономерности изменения электрической активности мышц практически полностью отражают трансформацию профиля электромиограммы мышц при ходьбе. Наиболее типичным является снижение средней электрической активности и суммарного интеграла, т.е. мощности и работы мышц в течение локомоторного цикла. Поэтому повышение активности при ходьбе на расстоянии 10 м обусловлено только возрастанием темпа и уменьшением длины шага.

Полученные данные указывают на необходимость дифференцированного подхода к реабилитационному процессу у детей с гемипаретической формой ДЦП.

Реабилитация детей с гемипаретической формой ДЦП младше 10 лет должна осуществляться так же, как и у детей с диплегической формой ДЦП, т.е. с двух сторон. В аспекте применения фазовой электрической стимуляции мышц это означает, что основным воздействием у больных этой группы является коррекция разгибания и отведения в обоих тазобедренных суставах посредством электрической стимуляции больших и средних ягодичных мышц. Поскольку такая коррекция обеспечивает устранение сгибательной установки ног, ее целесообразно сочетать со вспомогательными коррекциями, a именно с коррекцией тыльного сгибания в голеностопном суставе посредством электрической стимуляции передней большеберцовой мышцы. Указанная коррекция предотвращает задевание носком опорной поверхности и позволяет начать следующий шаг с опоры на пятку. Такая четырехканальная коррекция применяется у 70 \% детей первой группы. Меньшую роль играют другие коррекционные воздействия - четырехканальная стимуляция разгибания в обоих тазобедренных и коленных суставах посредством электрической стимуляции ягодичных мышц и трехглавых мышц голени или коррекция разгибания в обоих тазобедренных суставах и двусторонняя коррекция фронтальных наклонов туловища во второй половине опорной фазы.

Основными объектами коррекции движений у детей с гемипаретической формой ДЦП старше 10 лет является разгибание и отведение в тазобедренном суставе и тыльное сгибание в голеностопном суставе только на паретичной нижней конечности. Эта комбинация коррекционных воздействий при соответствующих показаниях может быть дополнена коррекцией сгибания в коленном суставе в опорную фазу шага - для уменьшения рекурвации (избыточного разгибания) в коленном суставе и в переносную фазу - для увеличения основного сгибания в том же суставе, а также коррекцией разгибания в плечевом и локтевом суставах посредством одновременной стимуляции задней порции дельтовидной мышцы и прямой головки трехглавой мышцы плеча в конце опорной и в течение переносной фазы.

$\mathrm{C}$ нашей точки зрения, данный подход к реабилитации у детей с гемипаретической формой ДЦП должен распространяться не только на метод фазовой электрической стимуляции мышц, но и на все остальные виды реабилитации.

\section{Выводы}

1. Разработка различных методов реабилитации детей с гемипаретической формой ДЦП должна осуществляться с учетом возраста.

2. Для ходьбы детей разного возраста с гемипаретической формой ДЦП характерно снижение скорости, темпа и длины шага, изменение временно́й структуры шага вследствие перефазировки опорной фазы и сокращения переносной фазы, уменьшение статической и динамической устойчивости, редукция амплитуды движений во всех суставах нижних конечностей, эквинусное положение в голеностопном суставе, снижение опорной и толчковой функций нижних конечностей, ослабление электрической активности мышц. 
3. Ходьба детей с гемипаретической формой ДЦП младше 10 лет отличается бо́льшей симметрией биомеханических и особенно электромиографических параметров.

4. У детей старше 13-14 лет оказывается сформированным более компенсированный вид гемипаретической походки, при которой дефект имеет отчетливый асимметричный, преимущественно дистальный характер и возмещается усилением работы мышц проксимальных отделов обеих ног.

5. Детям с гемипаретической формой ДЦП младше 10 лет следует рекомендовать тренировку симметричных мышц голени и ряда мышц бедра и таза (больших ягодичных, четырехглавых и двуглавых бедра).

6. Детям с гемипаретической формой ДЦП 13-14 лет может быть рекомендована более ограниченная система тренировки мышц, в основном на стороне пареза (передней большеберцовой, большой ягодичной мышц).

\section{СПИСОК ЛИТЕРАТУРЫ}

1. Витензон А.С. Закономерности нормальной и патологической ходьбы человека. - М.: Зеркало-М, 1998. - 272 c.

2. Витензон А.С., Иванов А.М., Гриценко Г.П., Петрушанская К.А. Реабилитация инвалидов с культей бедра посредством программируемой электростимуляции мышц при ходьбе. - М.: Зеркало, 2001. $176 \mathrm{c.}$

3. Витензон А.С., Миронов Е.М., Петрушанская К.А., Скоблин А.А. Искусственная коррекция движений при патологической ходьбе. - М.: Зеркало, 1999. - 503 с.

4. Витензон А.С., Петрушанская К.А. От естественного к искусственному управлению локомоцией. М.: МБН, 2003. -448 c.

5. Витензон А.С., Петрушанская К.А., Гриценко Г.П., Спивак Б.Г., Сутченков И.А. Особенности биомеханической структуры ходьбы у здоровых детей разного возраста // Российский журнал биомеханики. - 2013. - Т. 17, № 1. - С. 78-93.

6. Гриценко Г.П. Методы исследования энерготрат при ходьбе человека в норме и на протезе бедра: автореф. дис. ... канд. техн. наук. - М., 1975. - 21 с.

7. Гриценко Г.П., Витензон А.С., Славуцкий Я.Л., Сутченков И.А. Биомеханический комплекс для оценки ходьбы в норме и при нарушениях опорно-двигательного аппарата // Протезирование и протезостроение. - М.: ЦНИИПП, 1997. - Вып. 94. - С. 84-87.

8. Кожевникова В.Т. Современные технологии в комплексной физической реабилитации больных детским церебральным параличом. - М., 2005. - 240 с.

9. Пушкина С.В. Комплексная методика реабилитации больных ДЦП в поздней резидуальной стадии заболевания: автореф. дис. ... канд. мед. наук. - М., 2002. - 26 с.

10. Семенова К.А. Восстановительное лечение больных с резидуальной стадией детского церебрального паралича. - М.: Антидор, 1999. - 384 с.

11. Скворцов Д.В. Диагностика двигательной патологии инструментальными методами. Анализ походки. Стабилометрия. - М.: МБН, 2007. - 638 с.

12. Сологубов Е.Г. Система реабилитации больных с детским церебральным параличом методом динамической функциональной проприорецептивной коррекции: автореф. дис. ... д-ра мед наук. M., $1997-48$ c.

13. Сологубов Е.Г., Кожевникова В.Т., Ефременко В.Е. Результаты использования корректора движений в комплексном лечении детей с церебральным параличом // Вопросы современной педиатрии. 2003. - Т. 2. - Прил. 1. - С. 161.

14. Юнусов Ф.А., Ефимов А.П. Абилитация детей с церебральным параличом и его синдромами. - М.: Инфра-М, 2014. - 144 с.

15. Яворский А.Б., Сологубов Е.Г., Немкова С.А. Анализ походки больных с различными формами детского церебрального паралича // Медицинская техника. - 2003. - № 6. - С. 21-25.

16. Durham S., Eve 1., Turner-Simmonds C., Daniel C., Stevens C., Ewins D.J. An investigation of the effect of functional electrical stimulation to assist the gait of children with cerebral palsy // Proceedings of the 9-th Annual IFESS Conference. - Salisbary, 2004. - P. 74-76.

17. Freeman M. Cerebral palsy. - New York: Springer Science, 2005. - 1055 p.

18. Lee S.C.K., Stackhouse S.K., Stackhouse S.A., Schaefer M., McCarthy J.J., Smith B.T. Neuromuscular electrical stimulation and volitional training in children with cerebral palsy: a preliminary study // Proceedings of the 9-th Annual IFESS Conference. - Salisbary, 2004. - P. 71-73. 


\title{
BIOMECHANICAL AND NEUROPHYSIOLOGICAL FOUNDATION OF APPLICATION OF PHASE ELECTRICAL STIMULATION OF MUSCLES IN CHILDREN WITH HEMIPARETIC FORM OF INFANTILE CEREBRAL PALSY
}

\author{
A.S. Vitenson, K.A. Petrushanskaya, G.P. Gritsenko, \\ V.S. Shalygin, I.A. Sutchenkov (Moscow, Russia)
}

This work is devoted to biomechanical and electromyographic foundation of application of phase electrical stimulation of muscles in children with hemiparetic form of infantile cerebral palsy. Two groups of children with this form of infantile cerebral palsy of different age were under consideration - at the age of 8-10 (13 children) and at the age of 13-14 (12 children). Our investigations demonstrate that patients' age is of the decisive significance in elaboration of different rehabilitation programs, including program of phase electrical stimulation of muscles during walking. Walking of children of both groups is characterized by reduction of walking velocity, cadence and step length, decrease of stability, asymmetry of the temporal, kinematic, dynamic and electromyographic parameters. Nevertheless, greater symmetry of the biomechanical and especially of electromyographic parameters is seen in the first group of patients. In particular, general symmetrical decrease of activity of muscles of the lower extremities with accent to the muscles of the distal segments is observed in patients of this group. More compensated type of hemiparetic gait is formed in patients of the second group. In this case, the defect has distinct unilateral distal character and is considerably compensated by strengthening of work of muscles of the proximal segments of the lower extremities. The received results point to the necessity of the differential approach to rehabilitation of children with hemiparetic form of infantile cerebral palsy in dependence on their age. In particular, rehabilitation of children younger 10 must be realized by the same way as in children with diplegic form of infantile cerebral palsy, i.e. in both legs. In aspect of application of phase electrical stimulation, that means that correction of extension and abduction at both of the hip joints by means of electrical stimulation of both of m. gluteus maximus and both gluteus medius is the main influence in this group of children. It is expedient to combine this correction with the subsidiary corrections, namely with correction of the dorsal flexion at the ankle joint by means of electrical stimulation of $\mathrm{m}$. tibialis anterior. The following corrections are the main ones in children older 10: extension and abduction at the hip joint and dorsal flexion at the ankle joint, but only in the paretic lower extremity. From our point of view, such differential approach must be spread not only on the method of phase electrical stimulation of muscles during walking, but also on other methods of restoration of the motional functions during walking in patients with hemiparetic form of infantile cerebral palsy of different age.

Key words: hemiparetic form of infantile cerebral palsy, biomechanical and innervative structure of walking, phase electrical stimulation of muscles. 